\title{
The Teachergarten: Creating an Environment Conducive to Meaningful Teacher Growth
}

\author{
Candace Jaruszewicz - Mary Johnston White
}

Published online: 16 September 2009

(C) Springer Science+Business Media, LLC 2009

\begin{abstract}
This editorial provides discussion of conditions and actions needed to create and sustain a context and environment that is nurturing and conducive to meaningful professional teacher growth. The authors are a program director and master (lead) teacher from a university demonstration/laboratory program that is both state licensed and accredited through the National Association for the Education of Young Children. They frame the dialogue to address issues of (a) commitment to professional development as a long-term investment in program quality, (b) intellectual safety and challenge, (c) creative use of available resources, (d) respect for all stakeholders in the program, and (e) intentional modeling.
\end{abstract}

Keywords Professional development .

Early childhood education · Environment .

Program administration

Much of the research on teacher professional development in early childhood education focuses on teacher qualifications as a major program quality indicator and the means by which pre-service teachers should be initially prepared (Saracho and Spodek 2006, 2007). The continuing problem of high quality teacher retention, however, is frequently linked to compensation, external accountability demands, isolation, perceived lack of support, and stress as factors that contribute to high turnover and burnout (Hale-Jinks et al. 2006; Whitebook and Sakai 2003, 2004). Structured professional development and in-service opportunities are

C. Jaruszewicz $(\bowtie) \cdot$ M. J. White

N.E. Miles Early Childhood Development Center, College of Charleston, 91 Wentworth Street, Charleston, SC 29424, USA e-mail: jaruszewiczc@cofc.edu too often limited to immediate district or program needs (e.g. implementation of policies, record-keeping, etc.), ignoring the holistic development of a workplace culture intended to foster the intrinsic factors and motivation that can nourish teachers in even the most challenging of circumstances (Martin and Kragler 1999).

A professional climate can emerge and exist in every early childhood program. Whether it sustains and nurtures or neglects and ignores the needs of those within it, however, is a variable entirely dependent on many factors. Some conditions are beyond the control of the teaching staff and program director; early childhood teaching professionals are dependent to some extent on others external to their settings (legislators, policy makers, etc.) to plod forward toward some kind of anticipated resolution of these very critical issues. But as the director and a master teacher in our university demonstration and laboratory preschool/kindergarten program, we realize that we can't wait for that to happen. There are distinct actions and dispositions that can contribute to creation of a culture conducive to the intellectual and professional well-being of teachers. Program leaders and teachers need to take initiative to actively and intentionally create site-specific environments that support and nurture meaningful, satisfying, and intellectually challenging professional growth.

As the metaphor kindergarten, coined by Friedrich Froebel in the early nineteenth century, conveys the notion of a carefully tended classroom and learners, we propose the parallel term teachergarten for a professional environment where teacher reflection, ideas, and questions germinate, flourish, and are harvested to benefit the entire learning community. Regardless of program to program differences and challenges, we suggest growing conditions can be intentionally established through (a) commitment to professional development as a long-term investment in 
program quality, (b) ensuring intellectual safety and challenge, (c) creative use of available resources, (d) respect for all stakeholders in the program, and (e) intentional modeling.

\section{Commitment to Professional Development as a Long-Term Investment in Program Quality}

It is easy to view planning and scheduling professional development opportunities for staff as a chore; paperwork, documentation, and auditing/monitoring processes can also seem overwhelming. While most states that require annual training provide some kind of mechanism or system to deliver workshops, it seems too often program leaders tacitly approve or even openly encourage hit-or-miss and random selection of training opportunities for convenience sake that may have little to do with an individual teacher's real needs or interests. This situation, while meeting the letter of the law, does little to contribute to overall health and quality of the program. To use the garden metaphor, it's impossible to grow prize-winning orchids from wildflower seeds. Program leaders must explicitly and enthusiastically commit to relevant and high quality professional development opportunities for teachers and themselves.

Our experience is that the intrinsic value of sending teachers to a highly regarded conference (national, if possible) as opposed to evening or weekend local workshops can't be measured in immediate dollars. The real return on investment is teachers who feel professionally valued, supported, and satisfied, and who develop more serious and sustained commitment to the program. Further scaffolding occurs as teachers are encouraged (and expected) to share professional development experiences with one another in various ways. Teachers have both generally shared concerns and idiosyncratic questions about their practice and new understandings they wish to explore. Thus, individualized professional development plans are worth the effort they take to create. When teachers share ownership for their own growth and establish themselves as a community of learners, the energy produced by intellectual dialogue about their goals and aspirations infuses their work.

\section{Ensuring Intellectual Safety and Challenge}

In our program, teachers no longer begin a conversation with, "may I...." but are much more likely to say, "I've been thinking....", or "what if we were to....?" If teachers believe their ideas are not being received or valued, after a while they just stop offering them. Obviously, no growth can occur if this happens; subsequently, skepticism, cynicism, defeatism, and a lack of self-confidence that is destructive to the long-term health and quality of program and curriculum development may creep in. Program leaders who understand that their teaching staff represents a continuum of intellectual strength and potential, must also realize the value of conversational time, considering each individual in context and in the spirit with which thoughts and ideas are being offered.

In the children's book Muncha! Muncha! Muncha! (Fleming 2001), Mr. McGreely builds an ever stronger, higher, and deeper barricade to keep the rabbits out of his garden. We don't want our teachers to become like Mr. McGreely, working behind an invisible fence, becoming defensive in an environment that discourages dialogue and collaboration. Without an open-door approach, staff may retreat to their separate domains, and enthusiasm atrophies. A wise director seeks out teachers' ideas, actively listens, prompts with additional questions, and plans follow-up to demonstrate the value of their contributions as teachable moments. It is especially important that administrators be familiar with early childhood literature and share resources appropriate to teachers' ability levels and interests.

Just as ineffective as a director who doesn't listen, is the one who overwhelms teachers with information they either can't understand or that insults their intelligence. Like garden plants that need individual attention, specialized nutrients, and protection from pests and diseases, teacher thinking needs to be affirmed, nourished, and challenged. As lethal as weed killer on roses is the director who thinks he or she is the fount of all wisdom and that nothing can be learned from classroom teachers. A healthy intellectual environment is one in which everyone understands and believes that (a) the collective wisdom of the group as a sum of its parts enriches all, (b) there is no such thing as a dumb question, and (c) everyone represented among a program staff has something of value to teach to the others.

\section{Creative Use of Available Resources}

Who do we ask about how to gain access to the college's roof top planetarium? Is there a way that we can include art as in-class activity instead of a pull-out activity? Is there someone who can teach us how to work with clay, and where can we find a kiln to fire objects made with clay? Who can answer specific questions we have about local habitats? Over the last few years we have learned to be flexible in the way we think about all of the resources available to us as members of the college community and the neighborhood of which we are a part. We have been supported and encouraged by the response we have received by both communities. We have received visits from college experts and taken field trips to real science labs and art studios. We have explored parks and the bus 
system and discovered we can get almost anywhere from our center. This has expanded the possibilities available to us and turned our whole community into an extension of the classroom. In the process, the children have benefited by seeing how we are connected to each other and have grown in their sense of themselves as valuable members of a larger community.

Program and curriculum resources are incredibly important and often, more scarce than we would like. But teachers need to believe they have the ability to take an idea for a topic or unit, develop, and carry it out to the furthest extent practical and feasible. This can be very exciting and intimidating at the same time, especially as online and other authentic real-world/real-time electronic resources become more accessible. Reggio Emilia educators have inspired us to think of the community as our first and best resource (Edwards et al. 1998), for creating an atmosphere of discovery and intellectual adventure. Every program has potentially rich resources in its local neighborhood and especially among its (a) families and friends, (b) local commercial, industrial, and cultural communities, (c) civic organizations and government, and (d) regional academic institutions. What we have learned over time is that locating valuable resources is more a matter of initiative than convenience. The pottery gallery and studio two doors down the street is completely useless to us unless someone makes the effort to visit, meet the owner, share what we are doing with our kids, and establish the beginnings of a working relationship. We find that most people are flattered to be asked and usually more than willing to work with our children, but that the familiarity established with prior face-to-face contact can facilitate making arrangements.

Similarly, when funding for training is scarce, creativity is called for. When our travel budget was cut, we agreed to pool our funds so that two of the four teachers could attend a national conference one year, and two the next. Teachers together pored over the program, making requests for workshops and sessions that we agreed collectively would benefit all. The teachers who attended took notes, collected handouts, and presented the material as "mini-workshops" when they returned.

\section{Respect for All Stakeholders in the Program}

On-going communication between parents and teachers supports teacher growth as they rethink their practices in response to parent concerns and questions. It was because of parent observations about their children that we studied and learned about Autism and Aspberger's Syndrome, American Sign Language, applied behavior analysis, and re-thought scheduling to meet the needs of more active children. Similarly, when parents and other care-giving adults are invited to share their talents and interests in classroom activities, teacher content knowledge expands and the curriculum becomes richer and more authentic. We learned about bones, identifying herbivores and carnivores, and how to hatch butterflies and chickens from several parent biologists. We just finished a year teaching children poetry with a parent-poet, and implemented writing workshops with assistance from a parent who trained at Columbia Teachers College with Lucy Calkins (1994).

Unfortunately in some programs and schools, teachers' public pronouncements on the value of parental involvement and input are not always consistent with opinions they express privately, and it is somewhat discouraging to know that the real contributions families can make to support teachers and programs can be easily overlooked or viewed with less than deserved respect. It is thus important that program leaders implement policies, practices, and meaningful communications that include, value, and address the voices of parents as stakeholders in the program community.

Other stakeholders may not be so obvious, but may also have emotional and professional investment in the program and should be included in program dialogue. As part of a university, a whole host of individuals including other faculty, student observers, interns, researchers, physical plant and grounds crews, mail services, security, and custodial staff are present in our building regularly. They display genuine concern, pride, and affection for our teachers, parents, and children. They see the physical facility, our classroom environments, and curriculum documentation displays through a unique set of eyes. Their curiosity about activities and dedication as professionals in their own right often generate observations and questions that result in teaching initiatives, insights about children, or program improvements we may not have thought of otherwise.

\section{Intentional Modeling}

Finally, we assume and expect that individuals chosen for program leadership roles bring particular skills or dispositions drawn from their experiences and education that will benefit teachers, families, and children in both explicit and indirect ways. The administrator who imagines the reward for a leadership position as the power to tell everyone else what to do and how to do it is in for a rude surprise. Teachers and all program staff will look to the director or administrator as a role model, whether the leader wants them to do that or not. The challenge then becomes, not if you want to model behavior and dispositions, but how you will do so. Successful directors have a 
do as I do, not as I say mindset and model appropriate and desired professional behaviors, attitudes, and skills.

For example, when we made a decision to integrate technologies with curriculum and communications, teachers expressed anxiety about the amount of time and effort it would take aside from their already jam-packed days. To launch the initiative, the director piloted use of a program blog on our website and various online social-networking, document-sharing, photo-storage, and other digital tools. To use the garden metaphor once again, an effective program leader needs to demonstrate willingness to go beyond just creating and taking credit for the plan (or blame others when it doesn't work out) and actually help dig up the turf, get down in the dirt, plant seeds, and share weeding and watering responsibilities!

Program leaders who are good role models inspire teachers to transfer the qualities that sustain the teaching environment to the learning communities they are creating for children. If the program director demonstrates intellectual curiosity and risk taking, teachers feel safe and more willing to take risks. When they see an attitude of openness and respect for parents and other stakeholders in our program, they might think twice before speaking and be more inclined to try to look at a communication problem or issue from multiple perspectives. When they know what they say and think is valued, they will be more willing to seek supportive ways to engage with others and view inevitable disagreements as an opportunity for dialogue, rather than conflict. When the director seeks out their counsel and ideas for writing or research projects, they feel affirmed that their work contributes to the on-going mission of the program.

\section{Final Thoughts}

We certainly don't live and work in a perfect environment. But when we observe, for example, the progress of our 4 and 5 year old children's garden this year, we can't help but appreciate the parallels between what we have discussed here and what we see there. It did not grow from magic beans, but was a result of hard work, planning, collaborative effort, respect and understanding of individual differences, patience, and vision. Like an untended garden, without proper attention to teacher development, we believe an early childhood setting will be professionally inert, sowing seeds of dissatisfaction, dissention, and mediocrity rather than promoting healthy and robust growth and direction.

Nevertheless, sometimes despite our best efforts, we still lose good people or our plans go awry. We were reminded recently, when some of the fully grown plants in our children's "sunflower house" blew down in a summer storm, that successful gardening of all kinds requires perseverance and flexibility above all. As the children investigated and considered what had happened, one of them said, "Well, let's plant some new ones, and in the meantime, we have a window in our sunflower house we can look out of while we wait for them to grow!" Early childhood educators are challenged in many ways daily and their development can never be taken for granted or assumed. Commitment, intellectual safety and challenge, creative use of resources, respect for stakeholders, and intentional modeling are essential elements needed to create an environment conducive to sustained professional growth over time.

\section{References}

Calkins, L. (1994). The art of teaching writing. Portsmouth, NH: Heinemann Educational Books.

Edwards, C., Gandini, L., \& Forman, G. (1998). The hundred languages of children: The Reggio Emilia approach (2nd ed.). Westport, CT: Greenwood Publishing.

Fleming, C. (2001). Muncha, muncha, muncha. New York: Atheneum Books for Young Readers.

Hale-Jinks, C., Knopf, H., \& Kemple, K. (2006). Tackling teacher turnover in child care: Understanding causes and consequences, identifying solutions. Childhood Education, 82, 219-226.

Martin, L., \& Kragler, S. (1999). Creating a culture for teachers' professional growth. Journal of School Leadership, 9(4), 311-320.

Saracho, O. N., \& Spodek, B. (2006). Preschool teachers' professional development. In Bernard. Spodek \& Olivia. N. Saracho (Eds.), Handbook of research on the education of young children (2nd ed., pp. 423-429). Mahwah, NJ: Lawrence Erlbaum Associates, Publishers.

Saracho, O., \& Spodek, B. (2007). Early childhood teachers' preparation and the quality of program outcomes. Early Childhood Development and Care, 177, 71-91.

Whitebook, M., \& Sakai, L. (2003). Turnover begets turnover: An examination of job and occupational instability among child care center staff. Early Childhood Research Quarterly, 18(3), 273-293.

Whitebook, M., \& Sakai, L. (2004). By a thread: How child care centers hold on to teachers, how teachers build lasting careers. Kalamazoo, MI: W.E. Upjohn Institute for Employment Research. 